\title{
Demographic And Clinical Patterns of Stroke in Emergency in A Tertiary Care Hospital in North India
}

\author{
Dr. Rajiv Ratan Singh Yadav $^{1}$,Dr. Shiv Shanker Tripathi ${ }^{2}$,Dr. Sachin Avasthi ${ }^{3}$, \\ Dr.DeepakMalviya ${ }^{4}$,Dr.Abhishek Chauhan ${ }^{5}$. \\ ${ }^{1,2}$ Assistant Professor Emergency Medicine, Dr Ram Manohar Lohia Institute of Medical Sciences Lucknow \\ India, \\ ${ }^{3}$ Associate Professor Emergency Medicine, Dr Ram Manohar Lohia Institute of Medical Sciences Lucknow \\ India, \\ ${ }^{4}$ Prof and Head Departmentof Anaesthesiology, Dr Ram Manohar Lohia Institute of Medical Sciences Lucknow \\ India, \\ ${ }^{5}$ Assistant Prof Department of Radiology, Dr Ram Manohar Lohia Institute of Medical Sciences Lucknow India
}

\begin{abstract}
Background: Ischemic stroke, a subtype of acute stroke is one of the leading causes of death and major cause of morbidity and mortality throughout the world. The incidence is increasing with a gradual increase in obesity, diabetes mellitus, dyslipidemia, hypertension, and some other cardiac problem.

Objective: To find the demographic and clinical pattern of patients of stroke attending in the emergency medicine department.

Methods: This was a cross sectional observational study conducted in the Emergency Department in a tertiary care hospital in north India. All eligible patients clinically diagnosed as stroke (As defined by WHO. A clinical syndrome consisting of rapidly developing clinical signs of focal (or global in case of coma) disturbance of cerebral function lasting more than 24 hours or leading to death with no apparent cause other than a vascular origin) were included in this study.

Results: Out of the total stroke patients admitted, $60.2 \%$ were females and $39.8 \%$ were males. About one fourth of the patients were above 70 years of age (27.9\%). Convulsions was the most common clinical features (23.4\%) followed by altered sensorium (18.4\%), instability of gait (16\%), vomiting $(7.8 \%)$ and headache $(6.6 \%)$. Hypertension was found to be most common risk factor among the stroke patients (32.4\%). Hemiplegia was most common neurological finding (63.9\%).

Conclusion: The incidence of stroke was in older patients. The most common risk factor was found to be hypertension. Suitable measures to reduce the stroke risk can be adopted as primary and secondary prevention in these cases.
\end{abstract}

Keywords: Stroke, Incidence, Risk factors

\section{Introduction}

The risk factors for stroke vary internationally. Its risk factor profile may differ in different population groups. Details assessment of its underlying risk factors in stroke population of a country is relevant to understanding aetiology and planning preventive strategies to reduce future stroke burden ${ }^{[1]}$. Stroke is the second leading cause of death worldwide and one of the leading causes of disability. With increasing life expectancy, the burden of stroke is likely to increase worldwide with middle and low-income countries particularly affected. In a country like India, the cases are also increasing with gradual increase in obesity, diabetes mellitus, hyperlipidemia, hypertension, and some other cardiac problems. The incidence of stroke increases with age and the number of stroke is projected to increase as the number of the elderly population will increase. Stroke is a medical emergency and needs urgent diagnosis and treatment Ischemic stroke occurs due to loss of blood supply to part of the brain initiating the ischemic cascade due to free radical production and damage to endothelial lining.

Indian studies have shown that about $10-15 \%$ of strokes occur in people below the age of 40 years ${ }^{[4]}$. In India, nearly one-fifth of patients with first-ever strokes admitted to hospitals are aged $<40$ years ${ }^{[5]}$. Higher proportions of younger individuals are affected in India compared to developed countries. Ischemic stroke is the most common subtype followed by embolic stroke and $21-48 \%$ of stroke in young is caused by atherosclerotic large artery occlusive disease The present study was conducted to find the demographic and clinical pattern of patients of stroke attending in the emergency medicine department. 


\section{Material And Methods}

This was a cross sectional observational study conducted in the Emergency Department in a tertiary care hospital in north India. The study was approved by the Ethical Committee of the Institute. The consent was taken from each participant/attendant before enrolling in the study. All eligible patients clinically diagnosed as stroke (As defined by WHO. A clinical syndrome consisting of rapidly developing clinical signs of focal (or global in case of coma) disturbance of cerebral function lasting more than 24 hours or leading to death with no apparent cause other than a vascular origin) were included in this study. Likelihood of stroke was established by ROSIER SCALE and CT scan of brain (plain) which was performed in all the patients. Detail demographic and clinical history was taken. Mode of onset, progression since onset and associated symptom were noted. Proper general, physical and systemic clinical examinations was done as per clinical Performa and NIH STROKE SCALE -NIHSS was used for neurological assessment.

\section{Results}

Out of the total stroke patients admitted, $60.2 \%$ were females and $39.8 \%$ were males. About one fourth of the patients were above 70 years of age (27.9\%). However, $23.8 \%$ were between $61-70$ years and $21.7 \%$ were between 51-60 years of age (Table-1).Convulsions was the most common clinical features (23.4\%) followed by altered sensorium (18.4\%), instability of gait (16\%), vomiting (7.8\%) and headache (6.6\%) (Table-2).Table-3 shows the distribution of risk factors of stroke patients. Hypertension was found to be most common risk factor among the stroke patients (32.4\%). Dyslipidemia was the second most common risk factor (27.5\%). COPD/asthma was the least common risk factor $(4.9 \%)$.Hemiplegia was most common neurological finding (63.9\%) followed by any cranial nerve palsy (27.5\%) followed by decreased pupil size (15.6\%) and neck stiffness and Kernig sign (15.2\%) (Table-4).

\section{Discussion}

A medical emergency is morbidity that is acute and poses an immediate risk to life as well as long-term health making the emergency department of every a teaching institution as the backbone of hospital services. WHO has estimated that the emergency morbidity load will rise noticeably by the next few decades ${ }^{[7]}$. In the present study, the incidence of stroke was observed to be higher in the higher age groups and was lower in younger patients. This trend was seen in the studies done by Misbach and Wendra ${ }^{[8]}$, Shah et $\mathrm{al}^{[9]}$ and Zhang et $\mathrm{al}^{[10]}$, with $35.8 \%$ patients were $\geq 65$ years, $61.25 \%$ patients in $60-69$ years and $6.48 \%$ patients in $65-85$ years, respectively. In a study done by Baidya et al ${ }^{[11]}$, acute ischemic stroke was found most commonly in 50-75 age group. Young patients with ischemic stroke (age $\leq 45$ years) comprised of $17.14 \%$ of all patients. It correlated with the studies done by Misbach and Wendra ${ }^{[8]}$, Eapen et $\mathrm{al}^{[12]}$ and Shah et $\mathrm{al}^{[9]}$ with incidences of young patients with ischemic stroke were (12.9\% vs. $20 \%$ vs. $15.4 \%)$, respectively.In this study, females were predominance than males. This is in contrast to the study by Zhang et $\mathrm{al}^{[10]}$ and Baidya et $\mathrm{al}^{[11]}$ in which there was male predominance in ischemic stroke patients.In the present study, convulsions was the most common clinical features (23.4\%) followed by altered sensorium (18.4\%), instability of gait (16\%), vomiting (7.8\%) and headache $(6.6 \%)$.

In a study ${ }^{[3]}$, the most common clinical presentation was hemiplegia (49.1\%) followed by speech involvement $(29.1 \%)$, altered sensorium $(9.4 \%)$. In a study by $\mathrm{Abu}$ et $\mathrm{al}^{[13]}$, the most common clinical presentation was hemiplegia (80\%), speech involvement (60\%), altered sensorium (53.75\%) in ischemic stroke. In a study by Qari ${ }^{[14]}$ the most common feature was hemiplegia with $69 \%$, equal speech involvement and altered sensorium of $32 \%$. In the present study, hypertension was found to be most common risk factor among the stroke patients (32.4\%). Dyslipidemia was the second most common risk factor $(27.5 \%)$. COPD/asthma was the least common risk factor $(4.9 \%)$. Vaidya et $\mathrm{al}^{[3]}$ reported that the most common risk factor was hypertension with $(30.1 \%)$ incidence. Other major risk factors were previous history of cerebrovascular disease $(16.1 \%)$, dyslipidemia (15.6\%), smoking (15.1\%), diabetes mellitus (10.8\%), alcohol (6.5\%), history of previous coronary artery disease was $5.4 \%$, and 1 case of rheumatic heart disease $(0.5 \%)$. In study by Abu et al ${ }^{[13]}$, hypertension was most common with $(86.25 \%)$, (55\%) smokers, $(26.25 \%)$ diabetes mellitus, and (10\%) of cerebral infarction had previous history of stroke or transient ischemic attack. In the present study, hemiplegia was most common neurological finding (63.9\%) followed by any cranial nerve palsy (27.5\%) followed by decreased pupil size (15.6\%) and neck stiffness and Kernig sign (15.2\%).

\section{Conclusion}

The incidence of stroke was in older patients. The most common risk factor was found to be hypertension. Preventive strategies aimed at early detection and treatment of hypertension, public awareness about ill effects of cigarette smoking and excessive alcohol use can contribute in reduction of stroke burden. Suitable measures to reduce the stroke risk can be adopted as primary and secondary prevention in these cases. 


\section{References}

[1]. Maskey A, Parajuli M, Kohli S C. A Study of Risk Factors of Stroke in Patients Admitted in Manipal Teaching Hospital, Pokhara. Kathmandu Univ Med J 2011;36(4):244-7.

[2]. Smith WS, English JD, Johnson SC. Cerebrovascular diseases. In: Favei AS, Bravnald E, Kasper DL, Hsusor SL, Longo DL, Joneson J, et al., editors. Harrison's Principles of Internal Medicine. $18^{\text {th }}$ ed. USA: McGraw Hills; 2012. p. 2513-35.

[3]. Vaidya CV, Majmudar DK. A clinical study of ischemic stroke from capital of Gujarat, India. Sahel Med J 2015;18:177-81.

[4]. Feigin VL, Lawes CM, Bennett DA, Barker-Collo SL, Parag V. Worldwide stroke incidence and early case fatality reported in 56 population-based studies: A systematic review. Lancet Neurol 2009;8:355-69.

[5]. Pandian JD, Jaison A, Deepak SS, Kalra G, Shamsher S, Lincoln DJ, et al. Public awareness of warning symptoms, risk factors, and treatment of stroke in northwest India. Stroke 2005;36:644-8.

[6]. KMPG Emerging Trends in Health Care Report India. A Journey from Bench to Bedside. 2011.

[7]. Garg R, Aggarwal S, Singh H, Kajal KS, Garg R, Pal R. Study of the relation of clinical and demographic factors with morbidity in a tertiary care teaching hospital in India. Int J Crit Illn Inj Sci 2013;3:12-7

[8]. Misbach J, Wendra A. Clinical pattem of hospitalized strokes Clinical pattern of hospitalized strokes in 28 hospitals in Indonesia. Med J Indones 2000;9:29-34.

[9]. Shah PA, Bardi GH, Naiku BA, Khaliq A, Kaul RK. Clinico-radiological profile of strokes in Kashmir valley, North-West India: A study from a university hospital. Neurol Asia 2012;17:5-11.

[10]. Zhang J, Wang Y, Wang GN, Sun H, Sun T, Shi JQ, et al. Clinical factors in patients with ischemic versus hemorrhagic stroke in East China. World J Emerg Med 2011;2:18-23.

[11]. Baidya OP, Chaudhuri S, Devi KG. Clinico-epidemiological study of acute ischemic stroke in a tertiary hospital of Northeastern state of India. Int J Biomed Adv Res 2013;4:661-5.

[12]. Eapen RP, Parikh JH, Patel NT. A study of clinical profile and risk factors of cerebrovascular stroke. Gujarat Med J 2009;64:4854.

[13]. Abu Naser S, Nur N, Shahriar M, Alam B, Miah T. Clinical presentation and epidemiology of stroke - A study of 100 cases. J Med 2009;10:86-9.

[14]. Qari FA. Profile of stroke in a teaching university hospital in the western region. Saudi Med J 2000;21:1030-3.

Table-1: Age and sex distribution of stroke patients

\begin{tabular}{|l|c|c|c|c|c|c|}
\hline \multirow{2}{*}{ Age in years } & \multicolumn{2}{|c|}{ Male } & \multicolumn{2}{c|}{ Female } & \multicolumn{2}{c|}{ Total } \\
\cline { 2 - 7 } & No. & \% & No. & \% & No. & \% \\
\hline$<30$ & 4 & 30.8 & 9 & 69.2 & 13 & 5.3 \\
\hline $31-40$ & 8 & 40.0 & 12 & 60.0 & 20 & 8.2 \\
\hline $41-50$ & 13 & 40.6 & 19 & 59.4 & 32 & 13.1 \\
\hline $51-60$ & 24 & 45.3 & 29 & 54.7 & 53 & 21.7 \\
\hline $61-70$ & 25 & 43.1 & 33 & 56.9 & 58 & 23.8 \\
\hline$>70$ & 23 & 33.8 & 45 & 66.2 & 68 & 27.9 \\
\hline Total & 97 & 39.8 & 147 & 60.2 & 244 & 100.0 \\
\hline
\end{tabular}

Table-2: Distribution of clinical features of stroke patients

\begin{tabular}{|l|c|c|}
\hline \multicolumn{1}{|c|}{ Clinical features* } & $\begin{array}{c}\text { No. } \\
(\mathbf{n = 2 4 4})\end{array}$ & \% \\
\hline Altered sensorium & 45 & 18.4 \\
\hline Instability of gait & 39 & 16.0 \\
\hline Convulsions & 57 & 23.4 \\
\hline Headache & 16 & 6.6 \\
\hline Vomiting & 19 & 7.8 \\
\hline
\end{tabular}

*Multiple response

Table-3: Distribution of risk factors of stroke patients

\begin{tabular}{|l|c|c|}
\hline \multicolumn{1}{|c|}{ Risk factors* } & $\begin{array}{c}\text { No. } \\
(\mathbf{n = 2 4 4 )}\end{array}$ & \% \\
\hline Hypertension & 79 & 32.4 \\
\hline Diabetes & 57 & 23.4 \\
\hline Past history of CAD & 24 & 9.8 \\
\hline Dyslipidemia & 67 & 27.5 \\
\hline Alcohol & 35 & 14.3 \\
\hline Smoking & 58 & 23.8 \\
\hline Tobacco chewing & 36 & 14.8 \\
\hline COPD/Asthma & 12 & 4.9 \\
\hline Thyroid disorder & 26 & 10.7 \\
\hline Hepatitis & 11 & 4.5 \\
\hline Hypercholesterolaemia & 23 & 9.4 \\
\hline Heart disease & 13 & 5.3 \\
\hline
\end{tabular}

*Multiple response 
Demographic And Clinical Patterns Of Stroke In Emergency In A Tertiary Care Hospital In ...

Table-4: Distribution of neurological findings of stroke patients

\begin{tabular}{|l|c|c|}
\hline \multicolumn{1}{|c|}{ Neurological findings * } & $\begin{array}{c}\text { No. } \\
(\mathbf{n = 2 4 4})\end{array}$ & \% \\
\hline Any cranial nerve palsy & 67 & 27.5 \\
\hline Hemiplegia & 156 & 63.9 \\
\hline Neck stiffness and Kernig sign & 37 & 15.2 \\
\hline Decreased pupil size & 38 & 15.6 \\
\hline
\end{tabular}

*Multiple response 